\title{
Early iron-deficiency-induced transcriptional changes in Arabidopsis roots as revealed by microarray analyses Thomas J Buckhout ${ }^{1}$, Thomas JW Yang ${ }^{2}$ and Wolfgang Schmidt*2
}

\author{
Address: ${ }^{1}$ Institute of Biology, Humboldt University Berlin, Invalidenstraße 42, 10115 Berlin, Germany and ${ }^{2}$ Institute of Plant and Microbial \\ Biology, Academia Sinica, 115 Taipei, Taiwan \\ Email: Thomas J Buckhout - thomas.buckhout@cms.hu-berlin.de; Thomas JW Yang - thomasjwyang@gmail.com; \\ Wolfgang Schmidt* - wosh@gate.sinica.edu.tw \\ * Corresponding author
}

Published: 6 April 2009

BMC Genomics 2009, 10:147 doi:10.1186/147|-2164-10-147
Received: 8 December 2008

Accepted: 6 April 2009

This article is available from: http://www.biomedcentral.com/I47/-2/64/10/147

(C) 2009 Buckhout et al; licensee BioMed Central Ltd.

This is an Open Access article distributed under the terms of the Creative Commons Attribution License (http://creativecommons.org/licenses/by/2.0), which permits unrestricted use, distribution, and reproduction in any medium, provided the original work is properly cited.

\begin{abstract}
Background: Iron $(\mathrm{Fe})$ is an essential nutrient in plants and animals, and Fe deficiency results in decreased vitality and performance. Due to limited bio-availability of $\mathrm{Fe}$, plants have evolved sophisticated adaptive alterations in development, biochemistry and metabolism that are mainly regulated at the transcriptional level. We have investigated the early transcriptional response to $\mathrm{Fe}$ deficiency in roots of the model plant Arabidopsis, using a hydroponic system that permitted removal of Fe from the nutrient solution within seconds and transferring large numbers of plants with little or no mechanical damage to the root systems. We feel that this experimental approach offers significant advantages over previous and recent DNA microarray investigations of the $\mathrm{Fe}$ deficiency response by increasing the resolution of the temporal response and by decreasing nonFe deficiency-induced transcriptional changes, which are common in microarray analyses.
\end{abstract}

Results: The expression of sixty genes were changed after $6 \mathrm{~h}$ of Fe deficiency and $65 \%$ of these were found to overlap with a group of seventy-nine genes that were altered after $24 \mathrm{~h}$. A disproportionally high number of transcripts encoding ion transport proteins were found, which function to increase the Fe concentration and decrease the zinc $(\mathrm{Zn})$ concentration in the cytosol. Analysis of global changes in gene expression revealed that changes in $\mathrm{Fe}$ availability were associated with the differential expression of genes that encode transporters with presumed function in uptake and distribution of transition metals other than Fe. It appeared that under conditions of Fe deficiency, the capacity for $\mathrm{Zn}$ uptake increased, most probably the result of low specificity of the Fe transporter IRTI that was induced upon Fe deficiency. The transcriptional regulation of several $\mathrm{Zn}$ transports under Fe deficiency led presumably to the homeostatic regulation of the cytosolic concentration of $\mathrm{Zn}$ and of other transition metal ions such as $\mathrm{Mn}$ to avoid toxicity.

Conclusion: The genomic information obtained from this study gives insights into the rapid transcriptional responses to $\mathrm{Fe}$ shortage in plants, and is important for understanding how changes in nutrient availability are translated into responses that help to avoid imbalances in ion distribution. We further identified rapidly induced or repressed genes with potential roles in perception and signaling during Fe deficiency which may aid in the elucidation of these processes. 


\section{Background}

Iron is essential for numerous biological oxidation-reduction reactions in plants and plays a central catalytic role in all primary metabolic processes, including chlorophyll biosynthesis, photosynthetic and respiratory electron transport, nitrogen assimilation, and a large number of other anabolic and catabolic reactions [1]. In an oxidizing environment, the concentration of soluble $\mathrm{Fe}^{3+}$ is low and the Fe that is present is available to the cell typically in the form of ferric chelates. The mechanism for Fe uptake in Arabidopsis and all other dicotyledonous and non-grass monocotyledonous plants involves the reduction of $\mathrm{Fe}^{3+}$, release of $\mathrm{Fe}^{2+}$ from a chelate, and uptake of the liberated $\mathrm{Fe}^{2+}$ by the cell (strategy I; [2,3]). In Arabidopsis, the plasma membrane-bound $\mathrm{Fe}^{3+}$-chelate reductase FRO2 catalyzes the reduction of $\mathrm{Fe}^{3+}$ at the cell surface [4]. Homologues of FRO2 have been found in other strategy I plants such as pea [5], tomato [6], and cucumber [7]. The $\mathrm{Fe}^{2+}$ is then taken up by an Fe-deficiency-regulated transporter of the ZIP family, IRT1 [8,9]. In addition to transcriptional regulation, IRT1 and FRO2 are subject to posttranslational regulation, indicating the importance of an exact and rapid response by adjusting the amount of protein appropriate to the Fe demand in order to avoid the accumulation of surplus amounts of Fe [10,11]. The coordinated functions of IRT1 and FRO2 are principally responsible for Fe uptake in Arabidopsis roots [4,12,13].

Research in the regulation of the Fe deficiency response in plants has generated intense interest. The first insights into the nature of this regulation were based on the early discovery of the fer mutant in tomato [14]. The fer mutant (t3238fer) was unable to initiate the typical responses to Fe deficiency, including enhanced extrusion of protons, proliferation of root hairs, and $\mathrm{Fe}^{3+}$-chelate reductase activity. Furthermore, relatively low $\mathrm{Fe}$ concentrations (e.g. $0.1 \mu \mathrm{M}$ ) in the growth media were lethal [15]. The FER gene encodes a bHLH transcription factor that is expressed in roots and root tips but not in the leaves or upper hypocotyls [15]. The expression of FER was not greatly altered in tomato plants grown with 0.1 or $10 \mu \mathrm{M}$ Fe. Thus in tomato, FER is expressed in a root-specific and largely Fe-independent manner.

In Arabidopsis, FIT (AtbHLH029) was discovered as a FER homolog responsible for regulating the Fe deficiency response [16-19]. The genes FRO2 and IRT1 were found to be regulated by FIT, which also controls the expression of a total of 72 genes with known or putative functions in $\mathrm{Fe}$ homeostasis [16]. The transcriptional factor FIT was itself regulated by $\mathrm{Fe}$ deficiency; however, constitutive expression of FIT under the control of a $35 \mathrm{~S}$ promoter did not alter the expression patterns of IRT1 and FRO2, nor was the Fe content in the FIT over-expressing plants altered compared to controls [16]. It was concluded that FIT is necessary but not sufficient for regulation of the Fe deficiency response in Arabidopsis. Recently, it was demonstrated that FIT interacts with two bHLH transcription factors, AtbHLH038 and AtbHLH039 [20]. The overexpression of FIT with either AtbHLH038 or AtbHLH039 resulted in the constitutive expression of both IRT1 and FRO2 and the increased accumulation of Fe compared to controls. The function of AtbHLH038 and AtbHLH039 was shown by T-DNA insertion mutations to be redundant [21]. These results have led to the conclusion that an as yet unidentified cis-element is responsible for the $\mathrm{Fe}$ deficiency-associated regulation of IRT1 and FRO2 among other genes.

As in Arabidopsis, the mechanism of perception of Fe deficiency in grasses is still unknown. The cis-acting elements IDE1 and IDE2, which are presumably responsible for Fedeficiency-inducible expression, have been identified in the promoter region of the barley IDS2 gene [22]. A constitutively expressed transcription factor, IDEF1 belonging to the ABI3/VP1 family, has been shown to specifically bind to IDE1, and over-expression of IDEF1 led to the induction of the bHLH transcription factor OsIRO2 [23]. OsIRO2 expression was also induced by Fe deficiency, and OsIRO2 itself has been shown to bind to the cis-element 5'-CACGTGG-3' [24]. This cis-element was found in the promoters of a number of genes involved in Fe uptake in grasses. In particular, OsIRO2 was shown to be required for the transcriptional regulation of the genes involved in phytosiderophore synthesis and two transcription factor genes, OsNAC4 and a gene encoding an AP2 domainbinding protein. These later two transcription factors appeared to be regulated directly by OsIRO2 [25].

Recently, a transcription factor belonging to the NAC family, IDEF2, was found to bind specifically to the IDE2 element [26]. NAC transcription factors are a plant-specific family, which have been implicated in developmental responses to biotic and abiotic stress [27]. IDEF2 transcripts were constitutively expressed in shoots and roots and were not greatly altered under Fe deficiency. Reduction of IDEF2 transcript abundance by RNAi under conditions of Fe deficiency resulted in a considerable reduction in transcript abundance of the Fe-phytosiderophore transporter OsYSL2. At present, it appears that in grasses, the Fe-deficiency signal is mediated by at least two constitutively expressed transcription factors that under conditions of Fe deficiency, initiate a transcriptional cascade of events that lead to the adaptive responses to Fe deficiency.

There are similarities in the response pathway to Fe deficiency in Arabidopsis and rice (e.g. IDE1-like sequences and involvement of bHLH transcription factors), and based on our current knowledge, it is reasonable to expect a higher complexity in the response chain in Arabidopsis. 
The elucidation of regulatory components is rendered more difficult by the lack of knowledge on the temporal pattern of their expression. We present here a detailed time-course analysis of the short-term transcriptional changes induced by Fe deficiency by using DNA microarrays. We demonstrate that the majority of transcriptional changes were established within the first six hours after subjecting the plants to Fe deficiency. The transcriptional changes include most of the previously reported transcriptional changes in response to Fe deficiency but also novel transcripts that are likely to be important in transduction of the Fe deficiency response in Arabidopsis.

\section{Results}

The characterization of rapid responses to Fe deficiency at the transcriptome level requires a growth system that permits rapid removal of Fe from the media. Recently, various groups have published DNA microarray experiments using plants grown on agarose plates. Initiation of Fe deficiency was accomplished by transferring to Fe-deficient media, often in the presence of a $\mathrm{Fe}^{2+}$ chelator. Although widely used, the inherent drawbacks of the agar plate system include, inducing physical injuries to the plants during transferring, the roots carry-over of residual amounts of Fe-containing agarose, thus making the time-point of Fe deficiency difficult to determine, and lastly, the use of chelators that may affect the partitioning of metals across the plasma membrane independent of Fe deficiency. In the present study, we have used a well-characterized hydroponic system to analyze the Fe-deficiency response [28]. The system allowed the bulk transfer of a large number of plants with intact roots into Fe-sufficient or Fedeficient media within seconds and with minimal mechanical damage. Our approach allows for a timedependent monitoring of Fe deficiency-induced transcriptional changes with a clear-cut onset of the exposure to Fefree media. We have used this system to generate materials used in the present study.

\section{Time-course of Fe deficiency-induced alterations in transcript abundance}

To characterize the early response of transcript abundance to the removal of Fe from the growth media, differential gene expression was determined by DNA microarray analysis following 0, 0.5, 1, 6 and $24 \mathrm{~h}$ of Fe-deficient growth. For an initial characterization of the response to Fe deficiency, the genes were extracted from the data base that had a $p$-value of $<0.05$ and a fold change of $>50 \%$. These results are summarized in Venn diagrams for up- and down-regulated transcripts at very early ( 0 to $1 \mathrm{~h}$ ) and early ( 1 to $24 \mathrm{~h}$ ) time-points following removal of Fe (Figure 1). With only one exception, changes in transcript abundance at $0,0.5$ and $1 \mathrm{~h}$ were limited to a single time point, and the differentially expressed genes that were detected immediately after transfer or after 0.5 or $1 \mathrm{~h}$ of
Fe-deficient growth were not persistent over time. An examination of the over- or under-represented gene ontogeny categories (GO) showed no categories that were indicative of a response to Fe deficiency (Table 1). For these reasons, the genes showing differential expression at the $0,0.5$ and $1 \mathrm{~h}$ time points were considered to be Feunspecific responses.

Based on the total number of genes analyzed, approximately $0.3 \%$ of the transcripts were changed in abundance after $24 \mathrm{~h}$ of Fe-deficient growth. Furthermore, approximately $50 \%$ of the transcripts that showed a significant change in abundance after $24 \mathrm{~h}$ were already differentially expressed by $6 \mathrm{~h}$ (Figure 1). The GO categories that contained more than two members and that were over-represented at 6 and $24 \mathrm{~h}$ Fe deficiency were associated with cation transport processes and $\mathrm{Fe}$ homeostasis (Table 1). The 40 gene transcripts that were unique to the $24 \mathrm{~h}$ time-point showed no over-representation in ontogeny categories; whereas the transcripts unique to $6 \mathrm{~h}$ showed over-represented gene ontogeny categories for $\mathrm{Co} / \mathrm{Zn}$ detoxification, nicotianamine metabolism and $\mathrm{Cu}$ transport (data not shown). It was, however, clear that the early response to Fe deficiency was initiated between 1 and $6 \mathrm{~h}$ of growth under Fe-deficient conditions.

\section{Clustering of Fe-deficiency changes in gene expression}

To further characterize the response to Fe deficiency in a time-course manner, all data for transcript abundance at

Table I: A summary of over-represented GO categories of genes responding to Fe deficiencya

\begin{tabular}{|c|c|c|c|}
\hline $\begin{array}{l}\text { Treatment } \\
(\mathrm{h},-\mathrm{Fe})\end{array}$ & DEG & Gene Category & $p$ value, corrected \\
\hline 0 & 22 & none & \\
\hline \multirow[t]{2}{*}{0.5} & 80 & response to light stimulus & $1.7 \mathrm{e}-02$ \\
\hline & & carbon utilization & $3.6 \mathrm{e}-02$ \\
\hline I & 36 & sugar binding & 3. Ie-02 \\
\hline \multirow[t]{4}{*}{6} & 60 & transporter activity & 7.1e-02 \\
\hline & & iron ion binding & $2.4 \mathrm{e}-04$ \\
\hline & & response to metal ion & $1.3 e-03$ \\
\hline & & cation transport & $2.6 \mathrm{e}-02$ \\
\hline \multirow[t]{3}{*}{24} & 79 & iron ion binding & $3.83 \mathrm{e}-03$ \\
\hline & & ion transporter activity & $6.83 e-03$ \\
\hline & & C-C lyase activity & $3.43 e-02$ \\
\hline
\end{tabular}

a Transcript intensity was determined and differentially expressed genes (DEG) with an uncorrected $p<0.05$ and a change in intensity between Fe-sufficient and Fe-deficient treatments of $50 \%$ were selected for each of the five time points analyzed. Biological processes and molecular functions were determined as being over-expressed when a corrected $p<0.05$ was determined. The correction for false discovery rates was determined with Bingo software using the method of Benjamini and Hochberg [5I]. 

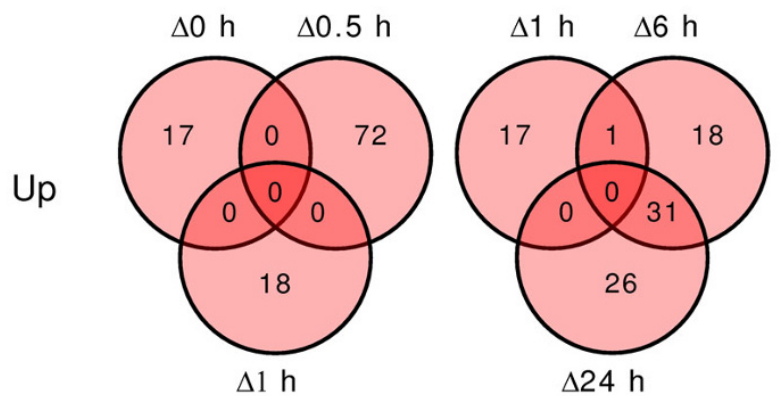

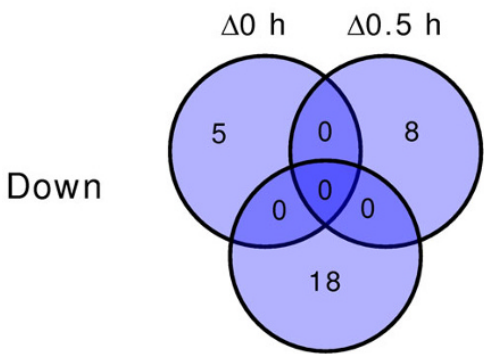

$\Delta 1 \mathrm{~h}$

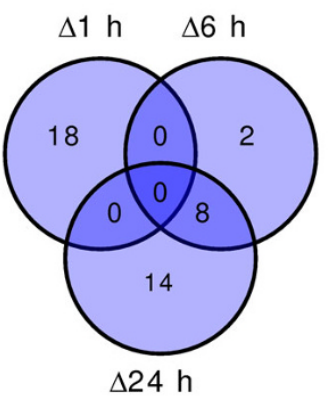

\section{Figure I}

Venn diagrams summarizing time- and Fe-dependent changes of transcript abundance in Arabidopsis roots. The intersections of the circles for the individual time points represent the number of genes whose transcript abundance with respect to the control treatments was increased (red, "up") or decreased (blue, "down"). For timedependent and Fe-dependent changes, gene transcripts were tallied whose $p$-score was $<0.05$.

0, 1, 6 and $24 \mathrm{~h}$ Fe deficiency were subjected to a cluster analysis using k-means methods with the algorithm as described previously [29]. The cluster stability was determined using the "benhur" function found in the clusterStab package of the Bioconductor software http:// www.bioconductor.org/. Apart from a two-cluster model that was not useful in analyzing the response to Fe deficiency, a six-cluster model generated the smallest number of clusters that gave the most stable results following multiple resorting. Therefore, the six-cluster model was used for further analysis. Clusters one and six showed transcripts with decreasing and increasing abundance during Fe-deficient growth, respectively (Figure 2). The significance of these trends was confirmed by a comparison of the transcript frequency in the top 200 statistically most altered transcripts with the frequency of transcripts in each cluster. The transcripts in cluster one and six were approximately 9- and greater than 60-fold overrepresented, respectively. Cluster four was slightly overrepresented in the top 200 transcripts, while the remaining clusters were slightly underrepresented. Clusters one and six clearly contained the majority of transcripts that were responding to Fe deficiency.

The fine structure of clusters one and six was investigated using heatmap diagrams and hierarchical clustering methods using Euclidian distances (Figure 3). Only transcripts with a $p<0.05$ were investigated. The transcript abundance in cluster one decreased during Fe-deficient growth. The decrease was weakly apparent after $1 \mathrm{~h}$ Fe-deficient growth and clearly evident at 6 and $24 \mathrm{~h}$. The kinetic behavior of individual transcripts was similar, with a small group of three transcripts showing a more pronounced response (Figure 3, cluster one). Prominent among the down-regulated transcripts in this group were the three ferritin genes, bacterial-type hemoglobin (GLB3) and the ZIP3 transporter. These genes have functions in Fe storage, binding and transport (Table 2). The biological processes of Fe transport and stimulus and the molecular functions of Fe binding and $\mathrm{Cu}$ and $\mathrm{Zn}$ transport were significantly over-represented in the genes showing a decrease in abundance (Figure 4). Interestingly, an overrepresentation in transcripts that encode proteins presumably localized in plastids was observed. Not surprisingly however, these transcripts included the ferritin genes but also components of the reductive pentose cycle.

The genes found in cluster six, which contained transcripts that responded with increasing abundance following removal of $\mathrm{Fe}$, could be divided into two subgroups by hierarchical clustering of approximately equal size. The first of these responded to Fe deficiency rapidly and with high increases in abundance already after $6 \mathrm{~h}$ of Fe deficiency (Figure 3). A tendency for increased abundance was apparent after $1 \mathrm{~h}$; although, this increase was not significant in all cases. Both of these groups contained a number of transcripts that were known to respond to Fe deficiency, including IRT1, IRT2, FRO3 and some bHLH transcription factors (Table 3). Genes encoding transport proteins and transcription factors were prominently represented in this group.

The second subgroup in cluster six responded more slowly to Fe deficiency and showed a significant increase in transcript abundance at $24 \mathrm{~h}$ of Fe-deficient growth with only slight increases after $6 \mathrm{~h}$. The increases after $6 \mathrm{~h} \mathrm{Fe-defi-}$ cient growth were in most cases not significant $(p>0.05)$. The behavior of this subgroup to Fe deficiency was similar to approximately one-third of the transcripts grouped into cluster four (Figure 3). When all clusters with a significantly increased abundance under Fe deficiency were reclustered, the group belonging to cluster four transcripts was associated with cluster six (Figure 3). The genes responding more slowly to Fe deficiency and belonging to cluster six are listed in Table 4 and those belonging to cluster four in Table 5. 


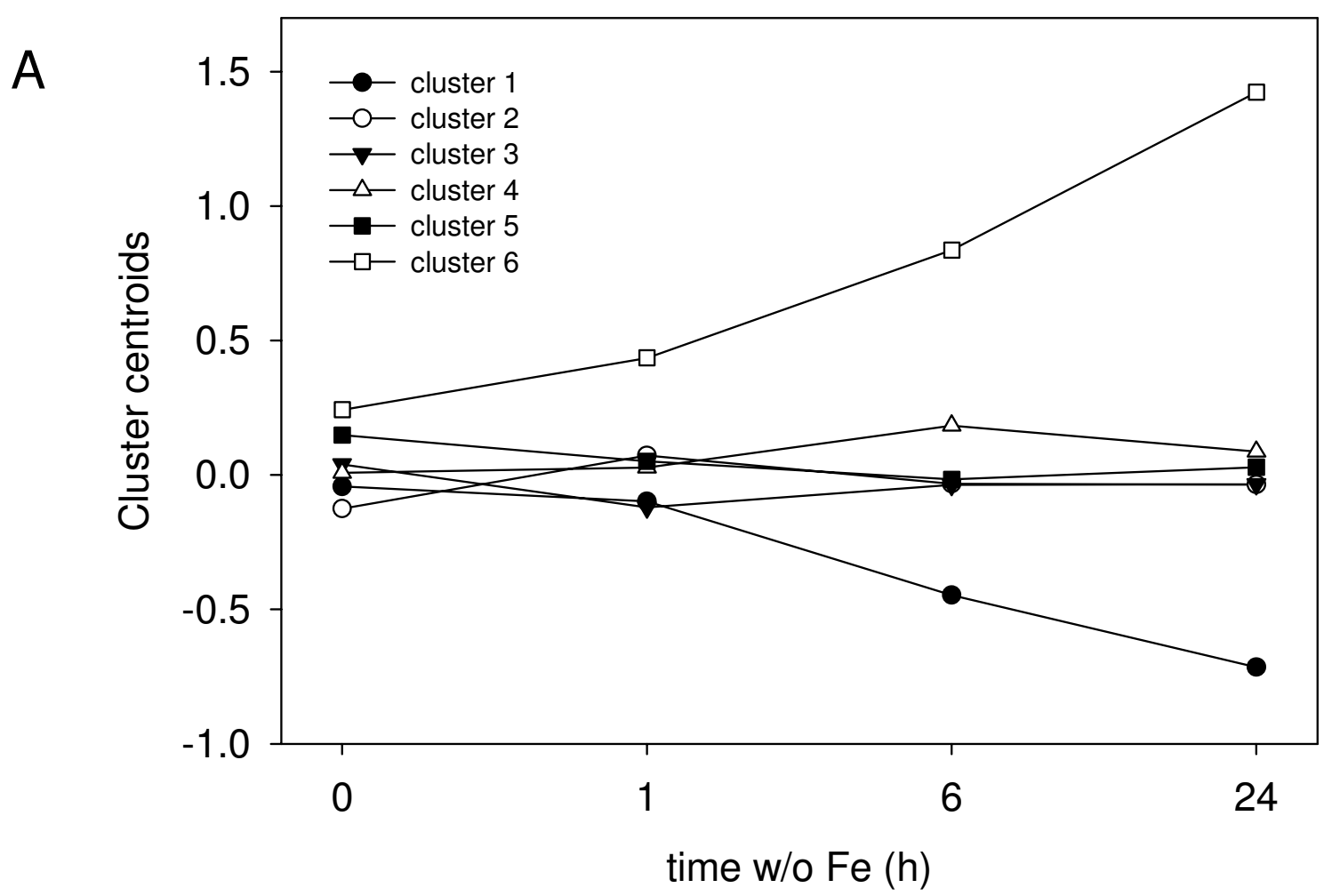

\begin{tabular}{|c|c|c|c|}
\hline Cluster\# & $\operatorname{Top}_{200}(\%)$ & All(\%)\# & $\mathrm{Top}_{200}$ (all) \\
\hline 1 & $16(8)$ & $195(0.9)$ & 8.9 \\
\hline 2 & $40(20)$ & $7182(31.5)$ & 0.6 \\
\hline 3 & $30(15)$ & $5364(27.9)$ & 0.5 \\
\hline 4 & $52(26)$ & $3626(15.9)$ & 1.6 \\
\hline 5 & $24(12)$ & $5370(23.5)$ & 0.5 \\
\hline 6 & $38(19)$ & $73(0.3)$ & 63.3 \\
\hline
\end{tabular}

Figure 2

The averaged response of clusters to Fe deficiency. The entire array dataset was subjected to a k-means cluster analysis, and the centroids of these clusters were plotted with respect to time $(A)$. The misrepresentation of significantly expressed gene transcripts is reported below the figure (B). For this analysis, the total frequency of genes found in a cluster was compared to the transcript frequency in the 200 statistically most significant signals.

Summarizing the general behavior of transcripts with increased abundance under Fe deficiency, GO categories related to the transport of $\mathrm{Fe}, \mathrm{Cu}$, oligopeptides and amino acids were strongly over-represented (Figure 5). Transcripts annotated to response to $\mathrm{Zn}$ and to detoxification of $\mathrm{Zn}$ and Co were predominant in this group. Furthermore, cellular components associated with the vacuole were over-represented, indicating the important role of the vacuole in the Fe-deficiency response.
Analysis of the differential response to Fe deficiency at the transcript level

The transcripts reported in Table 3 showed the greatest response to Fe deficiency based on fold-induction of any of the transcripts that were identified to be differentially regulated by Fe supply. To confirm the response of a portion of these transcripts to Fe deficiency, the transcript abundance of nine randomly chosen genes from Table 3 was analyzed by semi-quantitative PCR following Fe-defi- 
Table 2: List and description of genes transcripts down-regulated by Fe deficiency ${ }^{a}$

\begin{tabular}{|c|c|c|c|}
\hline Probe ID & ATG & Description & $p$-value \\
\hline 257823_at & At3g25190 & Integral membrane protein; putative nodulin & 0.047 \\
\hline 25II09_at & At5g0I600 & Ferritin I (ATFERI) & 0.000 \\
\hline 26I448_at & Atlg21 I40 & Similar to a nodulin-like protein & 0.034 \\
\hline 257807_at & At3g26650 & Glyceraldehyde 3-phosphate dehydrogenase A subunit (GapA), chloroplast & 0.012 \\
\hline 267526_at & At2g30570 & Photosystem II reaction center 6.IKD protein, (PsbW) protein-related & 0.041 \\
\hline 261691_at & Atlg50060 & Pathogenesis-related protein containing a SCP-like extracellular domain & 0.038 \\
\hline 263345_s_at & At2g05070 & Putative chlorophyll a/b binding protein; LHCIl type II & 0.038 \\
\hline 25|438_s_at & At3g59930 & Defensin-like (DEFL) protein & 0.001 \\
\hline 26383I_at & At2g40300 & Ferritin 4 (ATFER4) & 0.001 \\
\hline 266336_at & At2g32270 & A member of Zrt- and Irt-related protein (ZIP) family(ZIP3) & 0.002 \\
\hline 24994I_at & At5g22270 & Expressed protein with unknown function & 0.023 \\
\hline 25I735_at & At3g56090 & Ferritin 3 (ATFER3) & 0.007 \\
\hline 253393_at & At4g32690 & Expressed protein, 2-on-2 hemoglobin (GLB3) & 0.034 \\
\hline 262277_at & Atlg68650 & Expressed transmembrane protein of unknown function & 0.002 \\
\hline 263549_at & At2g21650 & MEE3 (maternal effect embryo arrest 3); myb-like transcription factor & 0.001 \\
\hline 263840_at & At2g36885 & Expressed protein with unknown function & 0.001 \\
\hline
\end{tabular}

a Listed are the genes in cluster I that showed a significantly $(p<0.05)$ decreased transcript abundance in response to Fe deficiency. The appearance in the list (top to bottom) corresponds to the order shown in Figure 3. Gene annotation is based on the 8.0 release of the Arabidopsis genome.

cient growth for $24 \mathrm{~h}$ and following Fe re-supply. As a well documented $\mathrm{Fe}$ response gene, FRO2 was included in the analysis for reference. In agreement with the published data, FRO2 and IRT1 were strongly up-regulated at $24 \mathrm{~h}$ following the removal of $\mathrm{Fe}$ from the growth medium (Figure 6). With the re-supply of $\mathrm{Fe}$, transcript abundance for these genes remained elevated over the subsequent $4 \mathrm{~h}$ compared to the Fe-sufficient controls. In two cases, At5g67370 and At4g16370, the response to Fe deficiency was generally weak and a clear response was not consistently observed. All other genes tested were strongly upregulated under conditions of Fe deficiency, thus confirming the results of the microarray experiments. Following the re-supply of $\mathrm{Fe}$, the transcript abundance of these individuals decreased rapidly after $1 \mathrm{~h}$ of re-supply, and in most cases no or only weak signals were observed after 4 $\mathrm{h}$ of Fe re-supply.

A quantitative validation of the microarray experiments was performed by real-time RT-PCR. The time-course of expression of six genes identified as being strongly induced by Fe deficiency (Table 3) was monitored over the experimental period (Figure 7). The changes in transcript abundance corresponded well with the Gene Chip signals, thus validating the data obtained from the microarray experiments.

\section{Discussion \\ Transcript abundance changes rapidly in response to $\mathrm{Fe}$ deficiency}

The general response of plants to Fe deficiency has been well documented, particularly with regards to Arabidopsis and rice [3]. It is still, however, largely unclear how the Fe status of the plant is perceived and which cellular compo- nents might be involved in signal perception. In many of the previous studies of gene expression during the response to Fe deficiency in Arabidopsis, plants were cultivated on agar plates and transferred to plates lacking $\mathrm{Fe}$ and often supplemented with a ferrous chelator to induce the response to Fe deficiency. In our opinion, the disadvantages to this approach are three fold. First, the agar plate method of induces more mechanical damage to the roots as a result of transfer, second, the inevitable contamination of a variable amount of $\mathrm{Fe}$-containing agar that was carried over during transfer, and last, the harsh side effects of extraction with ferrous chelates. In order to overcome these adverse effects, we have carried out the experiments using a hydroponics system that has been employed previously [28]. This system allows simultaneous transfer of a large number of plants to Fe-free media with little mechanical damage to the root system. Our current analysis of global gene expression during the early phases of the Fe-deficiency response demonstrated that the changes in transcript abundance relevant to the adaptive Fe stress response are occurring at the $6 \mathrm{~h}$ time point and time points following (Table 1 and Figure 1). In preliminary analyses that formed the basis of the investigation presented here, we determined the transcript abundance of representative genes that are known to respond to Fe deficiency (e.g. IRT1, FRO2 and FRO3). The result of that study showed that although changes in transcript abundance of $\mathrm{Fe}$ responsive genes could be observed at time-point prior to $6 \mathrm{~h}$, the response at and prior to $4 \mathrm{~h}$ was variable and the changes in transcript abundance that were observed did not persist (data not shown). Differential expression was observed immediately following transfer and after 0.5 and $1 \mathrm{~h}$ of growth in $\mathrm{Fe}$-depleted hydroponic culture media. However, these 


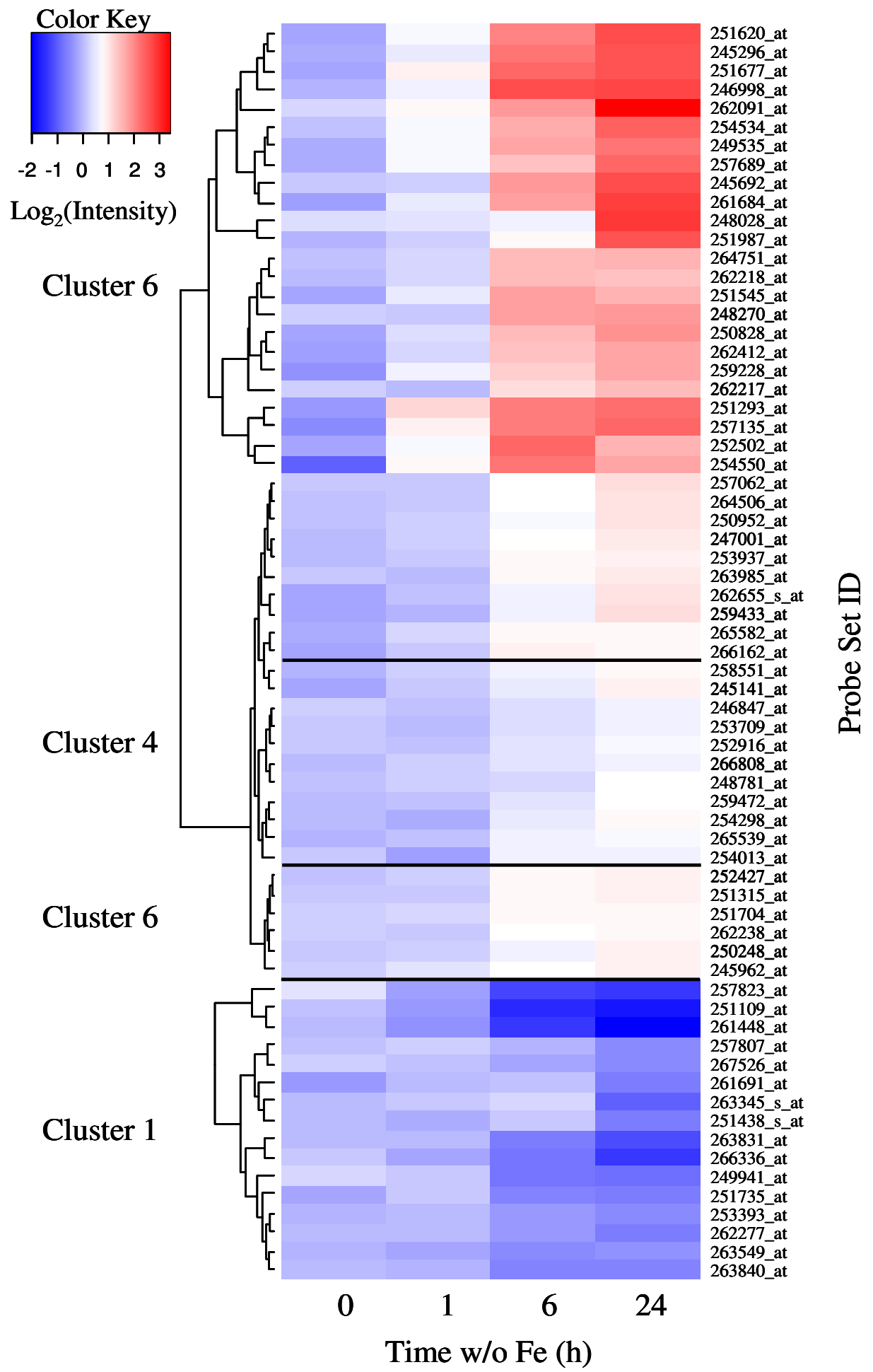

Figure 3

Heatmap analysis of changes in transcript abundance in Arabidopsis roots grown under Fe deficiency. The fine structure of clusters one and six were investigated. Changes in response to Fe deficiency with a $p$-value of $<0.05$ were selected for analysis. In a detailed analysis, several transcripts that were grouped into cluster 4 by an analysis of all transcripts showed an overlap with cluster six. The overlapping members of cluster 4 are also shown in the figure. 


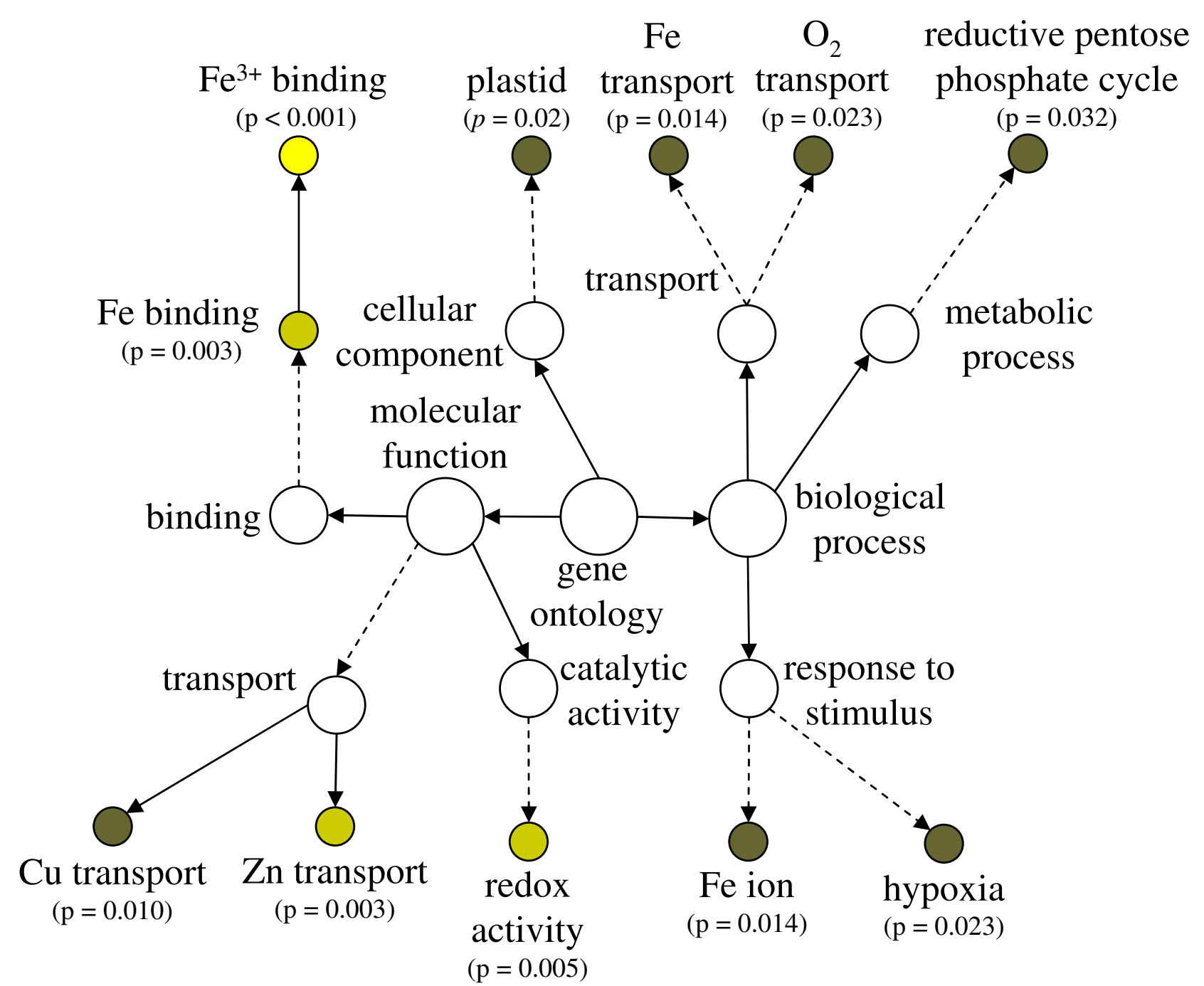

\section{Figure 4}

Over representation of gene ontogeny categories (GO) in genes showing decreased abundance under Fe deficiency. The genes, taken from Table 2, were analyzed using BinGO [50] and corrected for false discovery rate using the method of Benjamini and Hochberg [5I]. Dotted lines indicate intermediate categories that are not shown.

changes were restricted to individual time-points and the change were not continuous between the early timepoints. In fact, a large overlap in significantly changed gene expression was only observed between 6 and $24 \mathrm{~h} \mathrm{Fe}$ deficient growth (Figure 1).

The results from our study correspond well with a previous microarray analysis on the fit mutant by Colangelo and Guerinot [16]. Of the 72 genes that were identified by the previous study as being responsive to Fe deficiency with increased transcript abundance, 22 were also found in the present study. These 22 genes were distributed between early and late responding transcripts.

\section{Rapid transcriptional changes are associated with Fe} uptake and distribution

Considering the $\mathrm{Fe}$ deficiency-dependent and timedependent changes in transcript abundance, we have identified 16 genes whose abundance was decreased and 51 whose abundance was increased over the $24 \mathrm{~h}$ period. The decreased abundance in transcripts encoding two nodulin-like proteins (At3g25190 and At1g21140) was of particular interest, because these proteins contain a domain belonging to the CCC1-like family. The family of proteins with this domain includes a yeast vacuolar transmembrane protein (CCC1) that has been shown to transport Fe and Mn from the cytosol into vacuole [30] and 
Table 3: List and description of genes transcripts strongly up-regulated by Fe deficiency ${ }^{\mathrm{a}}$

\begin{tabular}{|c|c|c|c|}
\hline Probe ID & ATG & Description & $p$-value \\
\hline 251620_at & At3g58060 & Cation efflux family protein (MTPc3) & 0.001 \\
\hline 245296_at & At4gl6370 & Oligopeptide transporter (OPT3) & 0.000 \\
\hline 251677_at & At3g56980 & Basic helix-loop-helix transcription factor (BHLH039) & 0.006 \\
\hline 246998_at & At5g67370 & Expressed protein with unknown function & 0.005 \\
\hline 26209I_at & Atlg56160 & R2R3 transcription factor (MYB72) & 0.001 \\
\hline 254534_at & At4g19680 & $\mathrm{Fe}^{2+}$ transport protein (IRT2) & 0.008 \\
\hline 249535_at & At5g38820 & Amino acid transporter family protein & 0.026 \\
\hline 257689_at & At3gl2820 & Myb family transcription factor (MYBI0) & 0.002 \\
\hline 245692_at & At5g04I50 & Basic helix-loop-helix transcription factor (BHLHIOI) & 0.000 \\
\hline 261684_at & At $\lg 47400$ & Expressed protein with unknown function & 0.020 \\
\hline 248028_at & At5g55620 & Expressed protein with unknown function & 0.000 \\
\hline 251987_at & At3g53280 & Cytochrome P450 monooxygenase (CYP7IB5) & 0.022 \\
\hline 26475I_at & At $\lg 23020$ & $\mathrm{Fe}^{3+}$-chelate reductase (ATFRO3) & 0.008 \\
\hline 262218_at & Atlg74770 & Zinc finger ( $\mathrm{C} 3 \mathrm{HC} 4$-type RING finger) family protein & 0.016 \\
\hline 25I545_at & At3g58810 & Member of the zinc transporter (ZAT) family (ATMTPa2) & 0.048 \\
\hline 248270_at & At5g53450 & ORGI (OBP3-RESPONSIVE GENE I), serine/threonine protein kinases & 0.000 \\
\hline 250828_at & At5g05250 & Expressed protein with unknown function & 0.000 \\
\hline 2624I2_at & At $\lg 34760$ & I4-3-3 protein GFI4 omicron & 0.005 \\
\hline 259228_at & At3g07720 & Expressed protein with unknown function and containing a kelch repeat & 0.044 \\
\hline 262217_at & At lg74770 & Expressed protein with unknown function and containing a $\mathrm{Zn}$ binding domain & 0.005 \\
\hline 25I293_at & At3g6/930 & Expressed protein with unknown function & 0.044 \\
\hline 257I35_at & At3gl2900 & 2-OG-Fe ${ }^{2+}$ oxygenase family protein & 0.039 \\
\hline 252502_at & At3g46900 & Copper transport (COPT2) & 0.012 \\
\hline 254550_at & At4g 19690 & $\mathrm{Fe}^{2+}$ transport protein $(\mathrm{IRTI})$ & 0.039 \\
\hline
\end{tabular}

a Listed are the genes that showed a significantly $(p<0.05)$ increased in transcript abundance in response to Fe deficiency and whose intensity was shown in Figure 3 (Cluster 6, upper part). The list was sorted (top to bottom) to corresponds to the order shown in Figure 3 . Gene annotation is based on the TAIR 8.0 release of the Arabidopsis genome.

Table 4: List and description of genes transcripts weakly up-regulated by Fe deficiencya

\begin{tabular}{|c|c|c|c|}
\hline Probe ID & ATG & Description & $p$-value \\
\hline 257062_at & At3gl 8290 & Zinc finger protein, $\mathrm{C} 3 \mathrm{HC} 4$ type (RING finger) & 0.011 \\
\hline 264506_at & Atlg09560 & Germin-like protein (GLP5) & 0.027 \\
\hline 250952_at & At5g03570 & $\mathrm{Ni} /$ Fe transporter on the vacuole (ATIREG2) & 0.049 \\
\hline 24700I_at & At5g67330 & NRAMP metal ion transporter 4 (NRAMP4) & 0.000 \\
\hline 253937_at & At4g26890 & Mitogen-activated protein kinase kinase kinase 16 , MAPKKKI6 & 0.002 \\
\hline 263985_at & At2g42750 & Similar to DNAJ heat shock protein & 0.000 \\
\hline 262655_s_at & At $\lg 14190$ & Similar to glucose-methanol-choline (GMC) oxidoreductase family protein & 0.005 \\
\hline 259433_at & Atlg01570 & Similar to fringe-related protein & 0.001 \\
\hline 265582_at & At2g20030 & Identical to putative RING-H2 finger protein ATL2D precursor & 0.003 \\
\hline 266162_at & At2g28160 & Basic helix-loop-helix transcription factor (BHLH029) & 0.005 \\
\hline 252427_at & At3g47640 & Basic helix-loop-helix transcription factor (BHLH047) & 0.000 \\
\hline 251315_at & At3g61410 & Similar to protein kinase family protein, U-box domain-containing protein & 0.033 \\
\hline 25I704_at & At3g56360 & Expressed protein with unknown function & 0.005 \\
\hline 262238_at & Atlg48300 & Similar to soluble diacylglycerol acyltransferase & 0.003 \\
\hline 250248_at & At5g 13740 & ZIFI (ZINC INDUCED FACILITATOR I); carbohydrate transmembrane transporter & 0.009 \\
\hline 245962_at & At5g19700 & MATE efflux protein-related & 0.041 \\
\hline
\end{tabular}

a Listed are the genes that showed a significantly $(p<0.05)$ increased in transcript abundance in response to Fe deficiency and whose intensity was shown in Figure 3 (Cluster 6). The list was sorted (top to bottom) to corresponds to the order shown in Figure 3. Gene annotation is based on the TAIR 8.0 release of the Arabidopsis genome. 
Table 5: List and description of genes transcripts weakly up-regulated by Fe deficiency ${ }^{\mathrm{a}}$

\begin{tabular}{llll}
\hline Probe ID & ATG & Description & $p$-value \\
\hline 25855I_at & At3g06890 & Similar to oxidoreductase, transition metal ion binding & 0.027 \\
245I4I_at & At2g45400 & Homologous to dihydroflavonol 4-reductase and anthocyanidin reductase (BENI) & 0.007 \\
246847_at & At5g26820 & Ferroportin-related; similar to iron-responsive transporter-related & 0.006 \\
253709_at & At4g29220 & Similar to phosphofructokinase family protein & 0.005 \\
2529I6_at & At4g38950 & Kinesin motor family protein & 0.018 \\
266808_at & At2g29995 & Expressed protein with unknown function & 0.003 \\
24878I_at & At5g47870 & Expressed protein with unknown function & 0.017 \\
259472_at & AtIgl8910 & Expressed protein with protein binding/zinc ion binding domains & 0.040 \\
254298_at & At4g22890 & PGRLIA, a transmembrane protein present in thylakoids. & 0.004 \\
265539_at & At2gl5830 & Expressed protein with unknown function & 0.028 \\
2540I3_at & At4g26050 & Leucine-rich repeat protein & 0.023 \\
\hline
\end{tabular}

a Listed are the genes that showed a significantly $(p<0.05)$ increased in transcript abundance in response to Fe deficiency. The genes in this group clustered weakly into cluster six or overlapped with cluster four. The list was sorted (top to bottom) to corresponds to the order shown in Figure 3. Gene annotation is based on the TAIR 8.0 genome release.

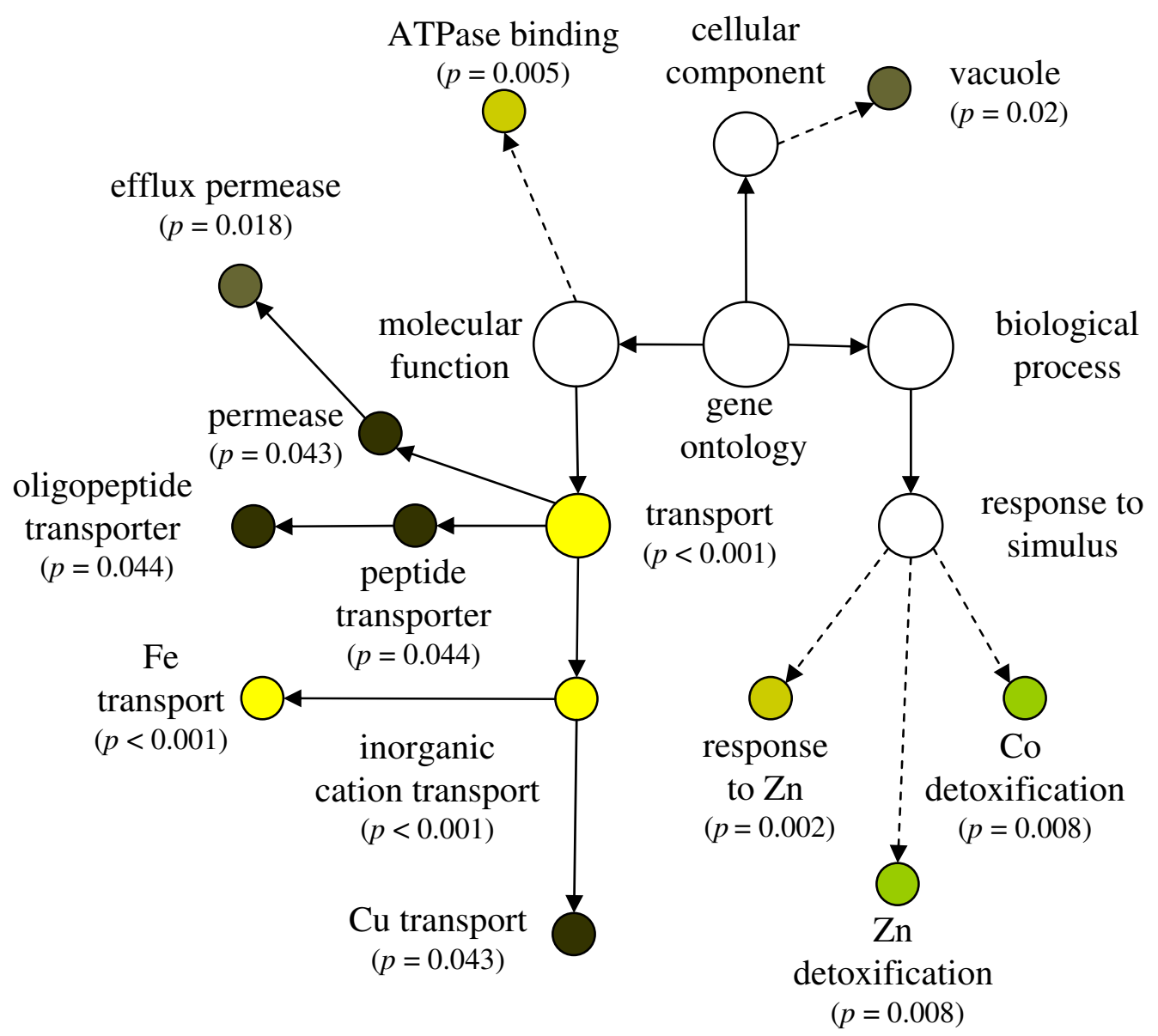

Figure 5

Over representation of gene ontogeny categories (GO) in genes showing increased abundance under Fe deficiency. The genes, taken from Table 3-4, were analyzed using BinGO [50] and corrected for false discovery rate using the method of Benjamini and Hochberg [5 I]. Dotted lines indicate intermediate categories that are not shown. 
At3g12820 - Myb10

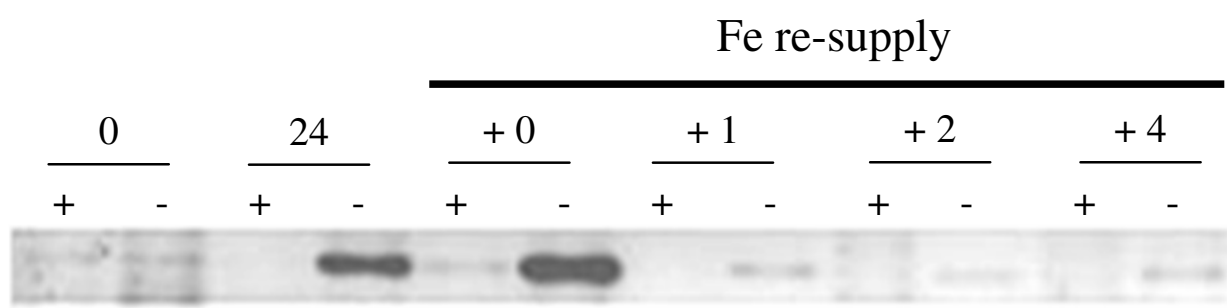

At3g56980 - bHLH101

At3g58060 - MTPc3

At5g04150 - bHLH039

At5g67370 - unknown

At5g38820 - AA Porter

At4g16370 - OPT

At3g07720 - GF14

At4g19690 - IRT1

At1g01580 - FRO2
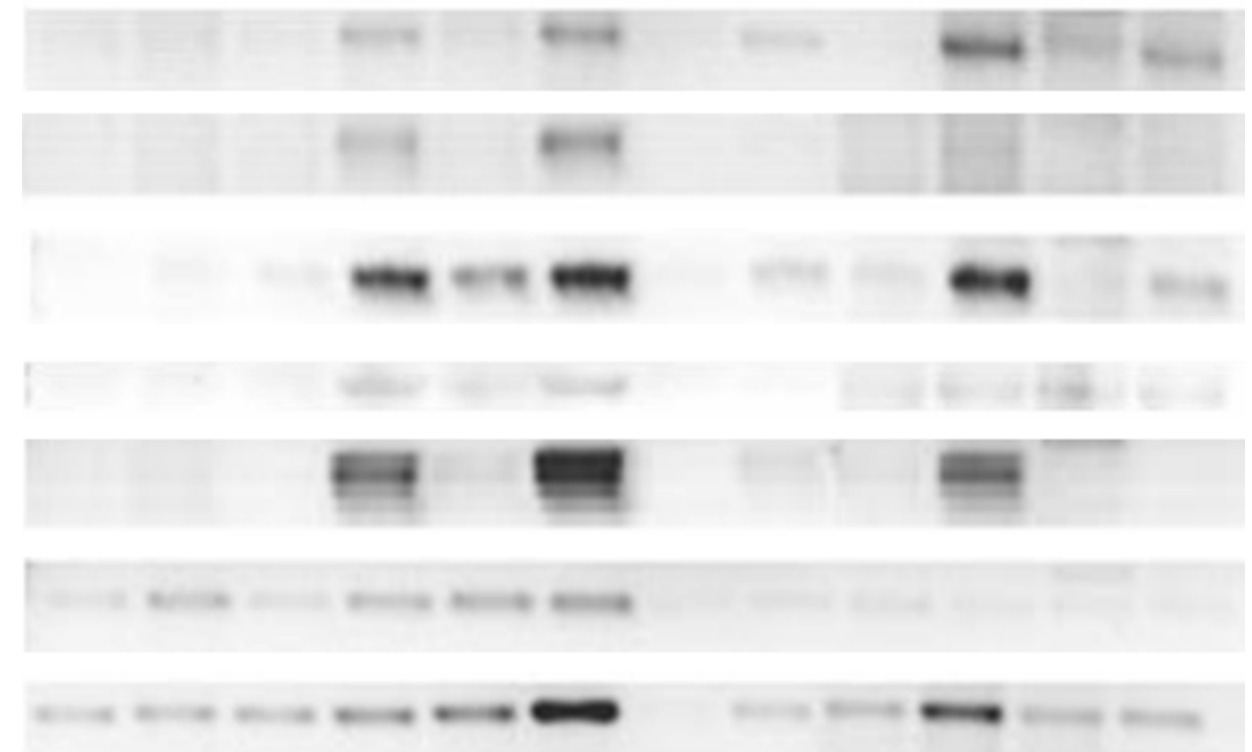

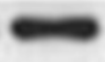

$+\infty$

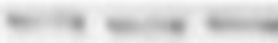

tine

$\mathrm{cm}$

Non

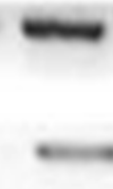

\section{At4g05320 - UBQ10}

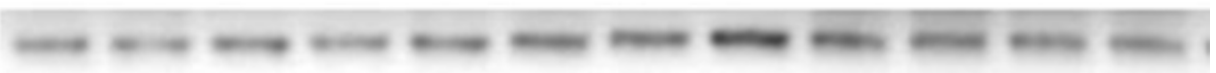

\section{Figure 6}

Semi-quantitative RT-PCR analysis of geneexpression. Plants were grown for $24 \mathrm{~h}$ with or without Fe and transferred to Fe-sufficient medium. Roots were harvested and analyzed by PCR as describe in the Materials and Methods. Nine genes were selected from Table 3 for analysis. RNA abundance in the different treatments was standardized using the ubiquitin 10 gene. The experiment was repeated once with similar results.

VIT1, a CCC1 homolog in Arabidopsis that has been shown to be an influx Fe transporter on the vacuolar membrane [31]. If the function of the two nodulin-like proteins were similar to VIT1, then the decreased abundance of these transcripts would be associated with a decreased capacity of the cell to store Fe in the vacuole. The decreased abundance in the three transcripts encoding ferritins was also easily understood in the context of Fe mobilization in response to deficiency.

Somewhat puzzling was the presence of three transcripts encoding chloroplast proteins in the group of most signif- icantly down-regulated transcripts (Table 2; At3g26650, At2g30570 and At2g05070). At3g26650 encodes one of the two subunits of the chloroplast glyceraldehyde-3phosphate dehydrogenase (GAPDH). This gene has been shown to be coordinately expressed with the phosphoribulokinase gene (PRK) and CP12-2 genes; however, in our study the three CP12-2 and the PRK genes showed no significant changes in response to Fe deficiency (data not shown). At2g30570 encodes a protein similar to subunit $\mathrm{W}$ of the photosystem II reaction center, and At $2 \mathrm{~g} 05070$ encodes Lhcb2.2, a member of the family of light-harvesting chlorophyll a/b-binding (LHC). How these transcripts 

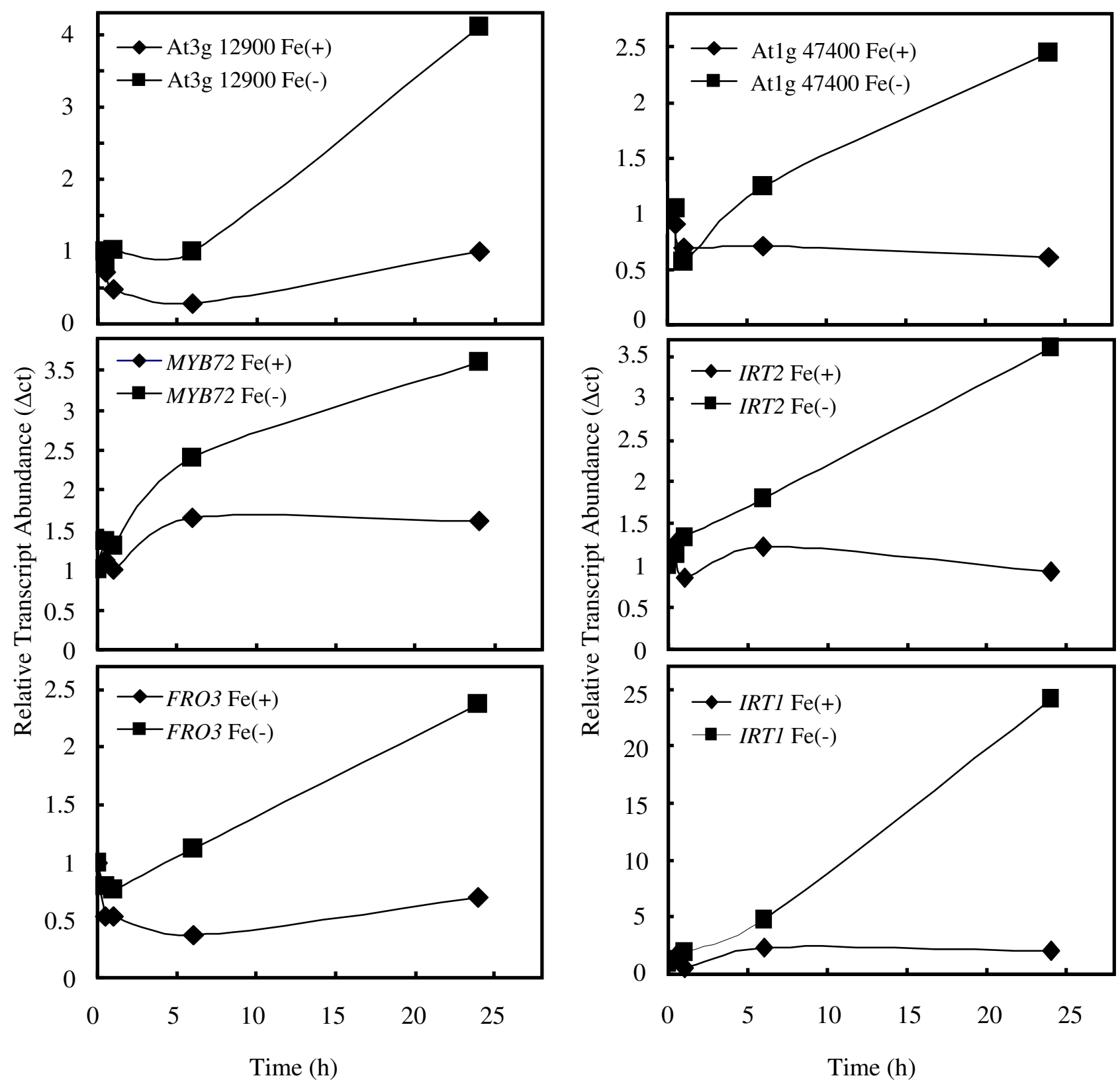

Figure 7

Real-time RT-PCR analysis of gene expression. Plants were transferred to either Fe-deficient or Fe-sufficient media and transcript abundance was monitored at times 0,6 and $24 \mathrm{~h}$ following the transfer. Roots were harvested and analyzed by qRTPCR as described in the Materials and Methods. Six genes were selected from Table 3 for analysis. RNA abundance in the different treatments was standardized using the $\alpha$-tubulin (At5g 19770) gene. The experiment was repeated twice with similar results.

might be involved in the root response to Fe deficiency is not known.

In contrast to the genes that displayed decreasing transcript abundance in response to Fe deficiency, gene which showed an increased in abundance formed a larger more heterogeneous group. They were subdivided further based on cluster analysis. One of these groups responded more rapidly the Fe deficiency (Table 3 ) than the other (Tables 4 and 5). As stated above, genes encoding Fe transporters, transcription factors and Fe-containing proteins were prominent among these up-regulated transcripts. With regard to metal transporters, the most rapidly responding transcripts were those encoding the Fe uptake transporters 


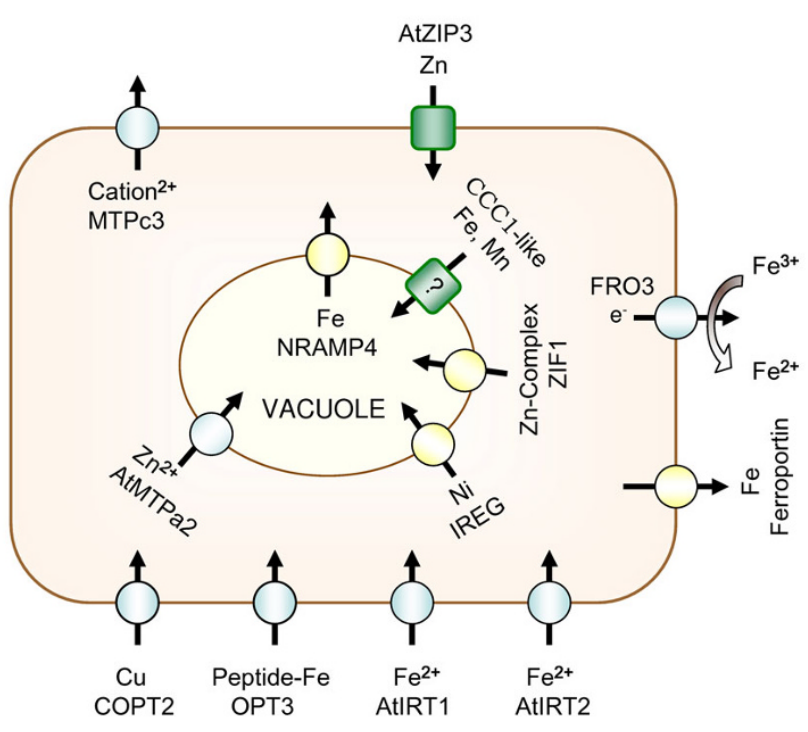

Figure 8

Summary of the immediate changes in ion transport in response to Fe deficiency. Squares were used to depict transporters with decreased and circles transporters with increased abundances. Yellow symbols represent changes that were observed only after $24 \mathrm{~h}$ of Fe deficiency, whereas the grey symbols were observed at both 6 and $24 \mathrm{~h}$. The genes encoding the proteins shown are: COPT2 (At3g46900, [4I]), OPT3 (At4gI6370, [34]), IRTI (At4gI9690, [9]), IRT2 (At4g 19680, [32]), Ferroportin (At5g26820, [36]), FRO3 (At lg23020, [33]), ZIP3 (At2g32270, [43]), MTPc3 (At3g58060, [38]), MTPa2 (At3g588I0, [39]), IREG2 (At5g03570, [42]), ZIFI (At5gI3740, [40]), CCCI-like (At3g25I90 [30] and NRAMP4 (At5g67330, [35]). The subcellular localization has been experimentally demonstrated for COPT2, IRTI, MTPa2, IREG2 and NRAMP4. Localization of the other proteins is hypothetical and was assumed according to their predicted function.

(IRT1 and IRT2 $[9,32]$ ), the $\mathrm{Fe}^{3+}$-chelate reductase FRO3 [33], and the oligopeptide-Fe transporter OPT3 [34]. The transcript abundance of NRAMP4, a vacuolar Fe efflux carrier [35], and of ferroportin, a putative Fe efflux carrier of unknown location [36], was increased at the $24 \mathrm{~h}$ time point but not before. Thus, based on the results of the present study, we suggest that the response of Arabidopsis to Fe deficiency was to increase and maintain the capacity for Fe uptake in the cytoplasm.

Recently, an investigation of the transcriptional response of Arabidopsis roots to abiotic stress, including the response to Fe deficiency, has been performed by Dinneny et al. using a cell sorting approach to increase the resolution of the analysis [37]. Upon reprocessing the microarray data published in that study using the methods and criteria concurrent with our own investigation, it was revealed that the number of transcripts which show a significant change was greater than 3100 , in contrast to less than 100 transcripts in the present study. While a considerable overlap was also found between the two studies, the individuals identified by Dinneny et al. [37] generally appeared after a longer exposure to Fe deficiency in the present study. In contrast, the differences in the respective studies can most likely be attributed to the different method of culturing the plants used in the experiments. However, possibly as a result of the high resolution of their systems, the majority of the transcripts identified in the Dinneny et al. [37] study appears to have no clear connection to the known responses to Fe deficiency and may represent, at least partly, biological signals unrelated to the Fe-deficiency response.

\section{Fe deficiency induces rapid changes in Zn homeostasis}

In addition to regulation of $\mathrm{Fe}$ transporter abundance under Fe deficiency, transcripts corresponding to $\mathrm{Zn}$ transporters were regulated under Fe deficiency. In this case, transcripts for the $\mathrm{Zn}$ plasma membrane efflux carrier, MTPc3 [38], and the vacuolar influx carrier, MTPa2 [39], were strongly and rapidly increased, while transcripts for the $\mathrm{Zn}$ plasma membrane influx carrier, ZIP3, were decreased. At the $24 \mathrm{~h}$ time-point, transcripts for the $\mathrm{Zn}$ vacuolar influx carrier, ZIF1 [40], were also increased. The effect of Fe deficiency was not restricted to Fe and $\mathrm{Zn}$. A Cu transporter [41] was rapidly increased and the Fe-regulated $\mathrm{Ni}$ transport was slowly increased [42]. ZIP3 (At2g32270) has been shown to be a $\mathrm{Zn}$ transporter that catalyzed $\mathrm{Zn}$ uptake when heterologically expressed in yeast [43]. ZIP3 responded to Zn deficiency [43], but a role for ZIP3 in Fe transport has not been shown.

\section{Conclusion}

A summary of the effects of Fe deficiency on ion transport in the cell is presented in Figure 8. Assuming that the regulation of transcript abundance is also reflected in altered ion fluxes in the cell, the response of the cell is to increase cytosolic Fe through increased influx into the cytosol and decreased efflux into the vacuole. On the other hand, rapid regulation of the gene transcripts MTPc3 and MTPa2 indicates changes associated with divalent cation homeostasis and have the effect of decreasing divalent cation influx into and increasing efflux out of the cytosol. The response of the cell to an increase cytosolic Fe concentration under conditions of Fe deficiency could be easily understood, whereas the opposite reaction to a reduction in the cytosolic $\mathrm{Zn}$ concentration is more difficult to explain. Perhaps under Fe deficiency the capacity for Zn uptake exceeded the nutritional requirement of the cells, and the cytosolic uptake as well as the efflux capacity was adjusted to establish a new $\mathrm{Zn}$ homeostasis. The specificity of the plant metal transporters may be the molecular cause for the deregulation of metal ion homeostasis dur- 
ing Fe deficiency. Recently, it was reported that a correlation between $\mathrm{Fe}$ deficiency and increased shoot concentrations of $\mathrm{Zn}, \mathrm{Mn}$ and $\mathrm{Co}$ [44]. Fe-deficient Arabidopsis roots accumulated high concentrations of $\mathrm{Co}, \mathrm{Mn}$ and Zn compared to nutrient sufficient controls $[9,10,45]$. Thus, a side effect of increasing the Fe uptake capacity is a concomitant uptake other metals via the IRT1 transporter, when the availability of $\mathrm{Fe}$ in the media is low.

The re-supply of Fe to Fe-deficient plants did not in all cases lead to a rapid down-regulation of genes which are highly induced by Fe-deficiency. In some cases, e.g. for bHLH101 and bHlH39 re-induction was observed $2 \mathrm{~h}$ after Fe resupply after an initial repression by Fe after $1 \mathrm{~h}$. Such an effect has been previously described for IRT1 and $\mathrm{FRO} 2$ and attributed to in the regulation of Fe-responsive genes by both local and systemic signals [46]. Our data demonstrate that this regulation is not restricted to IRT1 and FRO2, but also include genes with regulatory function.

\section{Methods}

\section{Plant Material and Growth Conditions}

Arabidopsis thaliana L. cv. Landsberg erecta was grown hydroponically in a growth chamber at a constant relative humidity of $75 \%$, under a $10 / 14 \mathrm{~h}$ light/dark cycle

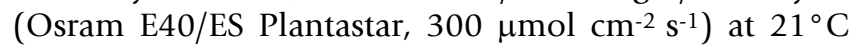
(day) or $18^{\circ} \mathrm{C}$ (night). Two to four seeds were sown in 1.5 $\mathrm{ml}$ Eppendorf tubes that were filled with $1 \mathrm{ml}$ of $0.25 \%$ agarose. The tip of the tube was cut off with a hot scalpel and the tubes were placed in black-plastic containers in contact with the nutrient solution that was constantly aerated. Each container contained approximately 45 Eppendorf tubes. At 20 days following sowing, the agarose plug was removed using a gentle stream of water. The nutrient solution was replaced weekly and at $24 \mathrm{~h}$ prior to beginning the experiment. The nutrient solution was composed of $\mathrm{KNO}_{3}(3 \mathrm{mM}), \mathrm{MgSO}_{4}(0.5 \mathrm{mM}), \mathrm{CaCl}_{2}(1.5 \mathrm{mM})$, $\mathrm{K}_{2} \mathrm{SO}_{4}(1.5 \mathrm{mM}), \mathrm{NaH}_{2} \mathrm{PO}_{4}(1.5 \mathrm{mM}), \mathrm{H}_{3} \mathrm{BO}_{3}(25 \mu \mathrm{M})$, $\mathrm{MnSO}_{4}(1 \mu \mathrm{M}), \mathrm{ZnSO}_{4}(0.5 \mu \mathrm{M}),\left(\mathrm{NH}_{4}\right)_{6} \mathrm{Mo}_{7} \mathrm{O}_{24}(0.05$ $\mu \mathrm{M}) \mathrm{CuSO}_{4}(0.3 \mu \mathrm{M})$, Fe-EDTA $(40 \mu \mathrm{M})$ with $\mathrm{pH}$ adjusted to 6.0 with $\mathrm{KOH}$ [47].

At 30 days after sowing, the plants were washed briefly in a $0.1 \mathrm{mM}$ EDTA solution and transferred into either Fefree or Fe-replete (controls) nutrient solutions. Following transfer, the roots were harvested after 0, 0.5, 1, 6 and 24 $\mathrm{h}$ into RNALater ${ }^{\circledast}$ (Applied Biosystems). The experiment was initiated $1 \mathrm{~h}$ into the light cycle. For each time-point analyzed, approximately 20 plants were harvested. The total processing time was approximately $15 \mathrm{~s}$. To confirm that the plants were responding to Fe deficiency, the $\mathrm{Fe}^{3+}$ chelate reductase activity was determined after $24 \mathrm{~h} \mathrm{Fe}$ deficiency using the method of Moog et al [48]. Only groups of Fe-deficient plants that showed a greater than
$80 \%$ increase in the $\mathrm{Fe}^{3+}$-chelate reductase at $24 \mathrm{~h}$ were used for RNA isolation. The data reported are averages taken from three independent experiments.

In the re-feeding experiments shown in Figure 6, 30-dayold plants were washed in $0.1 \mathrm{mM}$ EDTA as described above and transferred for $24 \mathrm{~h}$ to Fe-deficient media. Subsequently, samples were taken before transfer $(0 \mathrm{~h}$ control), following $24 \mathrm{~h}$ growth in Fe-deficient media (24 h $\mathrm{Fe}$ ) and following resupply of $\mathrm{Fe}$ at 0, 1,2 and $4 \mathrm{~h}$. Control plants were treated similarly but were grown in the presence of Fe.

\section{RNA Preparation and DNA-Microarray Hybridization}

Total RNA was extracted from roots (RNeasy ${ }^{\circledR}$ Midi Kit, Qiagen). The microarray analysis was performed using the Affymetrix ATH1 Arabidopsis GeneChip. The quality control of RNA, preparation of cRNA and hybridization of oligonucleotide chips was performed by the Affymetrix Gene Expression Service Lab. at the IPMB, Academia Sinica http://ipmb.sinica.edu.tw/affy/.

\section{Preprocessing and Statistical Analysis}

Preprocessing and statistical analysis of data was performed using the Bioconductor packages AffylmGUI and Limma ([49] http://www.bioconductor.org/). Arrays were normalized using the Robust Probe-level Linear Model (PLM) provided in the AffylmGUI package using the default parameters. Over- and under-represented gene ontogeny categories (GO) were determined using the program BiNGO 2.3 with Cytoscape 2.6 ([50] http:// www.psb.ugent.be/cbd/papers/BiNGO/) and the website Amigo http://amigo.geneontology.org. The correction for false discovery rates was determined with Bingo software using the method of Benjamini and Hochberg [51]. Cluster analysis was performed using the k-means methods with the algorithm of Hartigan and Wong [29]. The cluster stability was determined using the "benhur" function found in the clusterStab program of Bioconductor http:// www.bioconductor.org/.

All microarray data from this study have been deposited in NCBI Gene Expression Omnibus (accession number GSE15189).

\section{Semi-Quanitative RT-PCR}

cDNA was synthesized from one $\mu \mathrm{g}$ total RNA using an oligo-dT primer. The abundance of CDNA was standardized to the abundance of ubiquitin 10. The amount of cDNA was visualized by ethidium bromide staining following agrarose gel electrophoretic separation. The PCR primers for the genes tested were: AA-Transporter (At5g38820) fwd: ctacgcagctcatctcatgc, rev: cgattgcattggagaaaacc, bHLH039 (At3g56980) fwd: gctttggtgtttctgtttcg, rev: tcacttcgttgtcaccaagc, bHLH101 (At5g04150) fwd: 
ccgccgtagaaaacttaacg, rev: gacgtagcaatctggacagc, cation flux (At3g58060) fwd: ttcgtcaaacgatcatgagg, rev: tcttgtgcagctctctcagc, CYP71B5 (At3g53280) fwd: agaattggcgagagatgagg, rev: tggaaaaggctttcatcacc, FRO2 (At1g01580) fwd: cctaaatcagctgccgcacatgacg, rev: gttcacaaacattatgctcgtcgggc, IRT1 (At4g19690) fwd: ccccatggtcatggtcatgg, rev: attccaccgcaccogaag, kelch-repeat (At3g07720) fwd: taatttgcagcagagcaacg, rev: ttgagctcctggtgagtcg, Myb10 (At3g12820) fwd: caaaattggcgatctcttcc, rev: tttccccaaactcctcttcc, Myb72 (At1g56160) fwd: gaaaggaagagcaccatgc, rev: tttcccacatctcaacaatcc, OPT3 (At4g16370) fwd: ggaatgctctttgcttttgc, rev: gggctattagggtggtctcc, ubiqutin (At4g05320) fwd: ggaaaacaattggaggatgg, rev: ttagaaaccaccacgaagacg, unknown (At1g47400) fwd: gtctttgtcgcaaacttgg, rev: taggaaacaatcacgcagca, unknown (At5g55620) fwd: ccaaatgttcggctactcg, rev: ttgatatgcatgtggagagc, unknown (At5g67370), fwd: ggtttgacccacatttgtcc, rev: tgagtttctcgggtcaaagc, $\mathrm{Zn}$ binding (At1g74770) fwd: atgtttgcagggaaaagtgc, rev: gtaggagccacaggttgtgc

\section{Real-time RT PCR}

Total RNA was isolated from roots of 20 plants with RNeasy Plant Mini Kit (Qiagen) according to the manufacturer's instructions. Nucleic acid quantity was evaluated by using a NanoDrop ND-1000 UV-Vis Spectrophotometer (NanoDrop Technologies, Wilmington, USA). One $\mu \mathrm{g}$ of total DNase-treated RNA (Turbo DNase, Ambion) was reverse-transcribed using Superscript III Reverse Transcriptase (Invitrogen) with oligo dT primers in a total volume of $20 \mu \mathrm{L}$. Real-time quantitative PCR was performed using double-stranded DNA binding dye Syber Green PCR Master mix (Applied Biosystems) in an ABI GeneAmp 7000 Sequence Detection System. Each reaction was run in a triplicate and the melting curves were constructed using Dissociation Curves Software (Applied Biosystems), to ensure that only a single product is amplified. Validation experiments were performed to test the efficiency of the target amplification and the efficiency of the reference amplification. Duplicate $\mathrm{C}_{\mathrm{T}}$ values were analysed with Microsoft Excel using the comparative $\mathrm{C}_{\mathrm{T}}\left(\Delta \mathrm{C}_{\mathrm{T}}\right)$ method as described by the manufacturer (Applied Biosystems). The amount of target $\left(2^{-\Delta \Delta C_{T}}\right)$ was obtained by normalizing to an endogenous reference ( $\alpha$-tubulin, At5g19770) and relative to a calibrator (control tissue). The PCR primers for the genes tested were: FRO3 (At1G23020) fwd: ccatcactcctcaatcacttcca, rev: tccagccttgcttgccata, IRT1 (At4g19690) fwd: caccattcggaatagcgttagg, rev: ccagcggagcatgcattta, IRT2 (At4g19680) fwd: cgtatctccggcgatctca, rev: tgatgcacgggttatcaaagc, MYB72 (At1G56165) fwd: cgagaggtaaccaaatcgcaat, rev: tcttcaaatccgcatgggata, At3G12900 fwd: ccagcctctctctgagcgaat, rev: ctgggtagcctcacacgtaagg, At1G47400 fwd: ggcatatagtgagaatggtggtgat, rev: tcacgcagcaggagcataat

\section{Authors' contributions}

TJB led the experimental design of the present study, carried out the data analysis and drafted the manuscript. TJWY contributed to the design of the study, prepared RNA samples, conducted experiments to validate the microarray data, and was involved in editing of the manuscript. WS participated in the data analysis, strategic planning of the work, and writing of the manuscript. All authors read and approved the final manuscript.

\section{Acknowledgements}

Affymetrix GeneChip assays were performed by the Affymetrix Gene Expression Service Laboratory http://ipmb.sinica.edu.tw/affyl, supported by Academia Sinica. We thank Mr. Dirk Schubert for the PCR analysis shown in Figure 6. This work was supported by an Academia Sinica Pilot grant to TJB and WS.

\section{References}

I. Marschner H: Mineral Nutrition of Higher Plants. 2nd edition. London: Academic Press Ltd; 1995.

2. Römheld V, Marschner $\mathrm{H}$ : Evidence for a specific uptake system for iron phytosiderophres in roots of grasses. Plant Physiol 1986, 80(I): $175-180$

3. Curie C, Briat JF: Iron transport and signaling in plants. Annu Rev Plant Biol 2003, 54: I83-206.

4. Robinson NJ, Procter CM, Connolly EL, Guerinot ML: A ferricchelate reductase for iron uptake from soils. Nature 1999, 397:694-697.

5. Waters BM, Blevins DG, Eide DJ: Characterization of FROI, a pea ferric-chelate reductase involved in root iron acquisition. Plant Physiol 2002, I 29:85-94.

6. $\mathrm{Li}$ L, Cheng $X$, Ling HQ: Isolation and characterization of $\mathrm{Fe}$ (III)-chelate reductase gene LeFROI in tomato. Plant Mol Biol 2004, 54:125-136.

7. Waters BM, Lucena C, Romera FJ, Jester GG, Wynn AN, Rojas CL, Alcántara $E$, Pérez-Vicente R: Ethylene involvement in the regulation of the $\mathrm{H}(+)$-ATPase CsHAl gene and of the new isolated ferric reductase CsFROI and iron transporter CsIRTI genes in cucumber plants. Plant Physiol Biochem 2007, 45:293-30I.

8. Eide D, Broderius M, Fett J, Guerinot ML: A novel iron-regulated metal transporter from plants identified by functional expression in yeast. Proc Natl Acad Sci USA 1996, 93:5624-5628.

9. Vert G, Grotz N, Dédaldéchamp F, Gaymard F, Guerinot ML, Briat JF, Curie C: IRTI, an Arabidopsis transporter essential for iron uptake from the soil and for plant growth. Plant Cell 2002, 14: $1223-1233$.

10. Connolly EL, Fett JP, Guerinot ML: Expression of the IRT I metal transporter is controlled by metals at the levels of transcript and protein accumulation. Plant Cell 2002, I 4:347-I357.

II. Connolly EL, Campbell NH, Grotz N, Prichard CL, Guerinot ML: Overexpression of the FRO2 ferric chelate reductase confers tolerance to growth on low iron and uncovers posttranscriptional control. Plant Physiol 2003, I33: I I 02-I I I0.

12. Henriques R, Jásik J, Klein M, Martinoia E, Feller U, Schell J, Pais MS, Koncz C: Knock-out of Arabidopsis metal transporter gene IRTI results in iron deficiency accompanied by cell differentiation defects. Plant Mol Biol 2002, 50:587-597.

13. Varotto C, Maiwald D, Pesaresi P, Jahns P, Salamini F, Leister D: The metal ion transporter IRTI is necessary for iron homeostasis and efficient photosynthesis in Arabidopsis thaliana. Plant $J$ 2002, 31:589-599.

14. Brown JC, Chaney RL, Ambler JE: A new tomato mutant inefficient in the transport of iron. Physiol Plant 1971, 25:48-53.

15. Ling HQ, Bauer P, Bereczky Z, Keller B, Ganal M: The tomato fer gene encoding a bHLH protein controls iron-uptake responses in roots. Proc Natl Acad Sci USA 2002, 99:13938-13943.

16. Colangelo EP, Guerinot ML: The essential basic helix-loop-helix protein FITI is required for the iron deficiency response. Plant Cell 2004, 16:3400-34I2. 
17. Jakoby M, Wang HY, Reidt W, Weisshaar B, Bauer P: FRU (BHLH029) is required for induction of iron mobilization genes in Arabidopsis thaliana. FEBS Lett 2004, 577:528-534.

18. Yuan YX, Zhang J, Wang DW, Ling HQ: AtbHLH29 of Arabidopsis thaliana is a functional ortholog of tomato FER involved in controlling iron acquisition in strategy I plants. Cell Res 2005, 15:613-621.

19. Bauer P, Ling HQ, Guerinot ML: FIT, the FER-LIKE IRON DEFICIENCY INDUCED TRANSCRIPTION FACTOR in Arabidopsis. Plant Physiol Biochem 2007, 45:260-26I.

20. Yuan Y, Wu H, Wang N, Li J, Zhao W, Du J, Wang D, Ling HQ: FIT interacts with AtbHLH38 and AtbHLH39 in regulating iron uptake gene expression for iron homeostasis in Arabidopsis. Cell Res 2008, I 8:385-397.

2I. Wang HY, Klatte M, Jakoby M, Bäumlein H, Weisshaar B, Bauer P. Iron deficiency-mediated stress regulation of four subgroup Ib BHLH genes in Arabidopsis thaliana. Planta 2007 226:897-908.

22. Kobayashi T, Nakayama Y, Itai RN, Nakanishi H, Yoshihara T, Mori S, Nishizawa NK: Identification of novel cis-acting elements, IDEI and IDE2, of the barley IDS2 gene promoter conferring iron-deficiency-inducible, root-specific expression in heterogeneous tobacco plants. Plant / 2003, 36:780-793.

23. Kobayashi T, Ogo Y, Itai RN, Nakanishi H, Takahashi M, Mori S, Nishizawa NK: The transcription factor IDEF I regulates the response to and tolerance of iron deficiency in plants. Proc Natl Acad Sci USA 2007, 104:19150-19155.

24. Ogo Y, Itai RN, Nakanishi H, Inoue H, Kobayashi T, Suzuki M, Takahashi M, Mori S, Nishizawa NK: Isolation and characterization of IRO2, a novel iron-regulated bHLH transcription factor in graminaceous plants. J Exp Bot 2006, 57:2867-2878.

25. Ogo $Y$, Itai RN, Nakanishi H, Kobayashi T, Takahashi M, Mori S, Nishizawa NK: The rice bHLH protein OsIRO2 is an essential regulator of the genes involved in Fe uptake under Fe-deficient conditions. Plant J 2007, 5 I:366-377.

26. Ogo Y, Kobayashi T, Nakanishi Itai R, Nakanishi H, Kakei Y, Takahashi M, Toki S, Mori S, Nishizawa NK: A novel NAC transcription factor, IDEF2, that recognizes the iron deficiency-responsive element 2 regulates the genes involved in iron homeostasis in plants. J Biol Chem 2008, 283: | 3407- I 34 I 7.

27. Uauy C, Distelfeld A, Fahima T, Blechl A, Dubcovsky J: A NAC Gene regulating senescence improves grain protein, zinc, and iron content in wheat. Science 2006, 3 | 4: |2398- $1230 \mid$

28. Thimm O, Essigmann B, Kloska S, Altmann T, Buckhout T]: Response of Arabidopsis to iron deficiency stress as revealed by microarray analysis. Plant Physiol 200 I, I 27: 1030-1043.

29. Hartigan A, Wong MA: A k-means clustering algorithm. Appl Statist 1979, 28:100-108.

30. Li L, Chen OS, McVey Ward D, Kaplan J: CCCI is a transporter that mediates vacuolar iron storage in yeast. I Biol Chem 2001 , 276:29515-29519.

31. Kim SA, Punshon T, Lanzirotti A, Li L, Alonso JM, Ecker JR, Kaplan J, Guerinot ML: Localization of iron in Arabidopsis seed requires the vacuolar membrane transporter VITI. Science 2006, 3 | 4: | 295- I 298.

32. Vert G, Briat JF, Curie C: Arabidopsis IRT2 gene encodes a rootperiphery iron transporter. Plant J 200I, 26:181-I89.

33. Mukherjee I, Campbell NH, Ash JS, Connolly EL: Expression profiling of the Arabidopsis ferric chelate reductase (FRO) gene family reveals differential regulation by iron and copper. Planta 2006, 223: II78-I190.

34. Stacey MG, Patel A, McClain WE, Mathieu M, Remley M, Rogers EE, Gassmann W, Blevins DG, Stacey G: The Arabidopsis AtOPT3 protein functions in metal homeostasis and movement of iron to developing seeds. Plant Physiol 2008, I 46:589-60 I.

35. Lanquar $V$, Lelièvre $F$, Bolte $S$, Hamès $C$, Alcon $C$, Neumann $D$, Vansuyt G, Curie C, Schröder A, Krämer U, Barbier-Brygoo H, Thomine S: Mobilization of vacuolar iron by AtNRAMP3 and AtNRAMP4 is essential for seed germination on low iron. EMBO J 2005, 24:404 I-405I.

36. Wintz H, Fox T, Wu YY, Feng V, Chen W, Chang HS, Zhu T, Vulpe $C$ : Expression profiles of Arabidopsis thaliana in mineral deficiencies reveal novel transporters involved in metal homeostasis. J Biol Chem 2003, 278:47644-47653.

37. Dinneny JR, Long TA, Wang JY, Jung JW, Mace D, Pointer S, Barron C, Brady SM, Schiefelbein J, Benfey PN: Cell identity mediates the response of Arabidopsis roots to abiotic stress. Science 2008 , 320:942-945

38. Mäser P, Thomine S, Schroeder JI, Ward JM, Hirschi K, Sze H, Talke IN, Amtmann A, Maathuis FJ, Sanders D, Harper JF, Tchieu J, Gribskov M, Persans MW, Salt DE, Kim SA, Guerinot ML: Phylogenetic Relationships within Cation Transporter Families of Arabidopsis. Plant Physiol 200I, I 26:1646-1667.

39. Arrivault S, Senger T, Krämer U: The Arabidopsis metal tolerance protein AtMTP3 maintains metal homeostasis by mediating Zn exclusion from the shoot under Fe deficiency and Zn oversupply. Plant J 2006, 46:86I-879.

40. Haydon MJ, Cobbett CS: A novel major facilitator superfamily protein at the tonoplast influences zinc tolerance and accumulation in Arabidopsis. Plant Physiol 2007, I 43: I705-1719.

4I. Sancenón V, Puig S, Mira H, Thiele DJ, Peñarrubia L: Identification of a copper transporter family in Arabidopsis thaliana. Plant Mol Biol 2003, 5 I :577-587.

42. Schaaf G, Honsbein A, Meda AR, Kirchner S, Wipf D, von Wirén N AtIREG2 encodes a tonoplast transport protein involved in iron-dependent nickel detoxification in Arabidopsis thaliana roots. B Biol Chem 2006, 28 I:25532-25540.

43. Grotz N, Fox T, Connolly E, Park W, Guerinot ML, Eide D: Identification of a family of zinc transporter genes from Arabidopsis that respond to zinc deficiency. Proc Natl Acad Sci USA 1998, 95:7220-7224.

44. Baxter IR, Vitek O, Lahner B, Muthukumar B, Borghi M, Morrissey J, Guerinot ML, Salt DE: The leaf ionome as a multivariable system to detect a plant's physiological status. Proc Natl Acad Sci USA 2008, I05:208|-12086.

45. Korshunova YO, Eide D, Clark WG, Guerinot ML, Pakrasi HB: The IRTI protein from Arabidopsis thaliana is a metal transporter with a broad substrate range. Plant Mol Biol 1999, 40:37-44.

46. Vert GA, Briat JF, Curie C: Dual regulation of the Arabidopsis high-affinity root iron uptake system by local and long-distance signals. Plant Physiol 2003, I32:796-804.

47. Schmidt W: Root-mediated ferric reduction: responses to iron deficiency, exogenously induced changes in hormonal balance and inhibition of protein synthesis. J Exp Bot 1994, 45:725-73।

48. Moog PR, Kooij TA van der, Brüggemann W, Schiefelbein JW, Kuiper P]: Responses to iron deficiency in Arabidopsis thaliana: The Turbo iron reductase does not depend on the formation of root hairs and transfer cells. Planta 1995, I95:505-5I3.

49. Wettenhall JM, Simpson KM, Satterley K, Smyth GK: A ylmGUI: a graphical user interface for linear modeling of single channel microarray data. Bioinformatics 2006, 22:897-899.

50. Maere S, Heymans K, Kuiper M: BiNGO: a Cytoscape plugin to assess overrepresentation of Gene Ontology categories in biological networks. Bioinformatics 2005, 2 I:3448-3449.

5I. Benjamini $Y$, Hochberg $Y$ : Controlling the false discovery rate: a practical and powerful approach to multiple testing. J R Statist Soc B 1995, 57:289-300.

Publish with Biomed Central and every scientist can read your work free of charge

"BioMed Central will be the most significant development for disseminating the results of biomedical research in our lifetime. "

Sir Paul Nurse, Cancer Research UK

Your research papers will be:

- available free of charge to the entire biomedical community

- peer reviewed and published immediately upon acceptance

- cited in PubMed and archived on PubMed Central

- yours - you keep the copyright
BioMedcentral 